ISSN 2620-6760, Vol.4, No. 1, April 2021

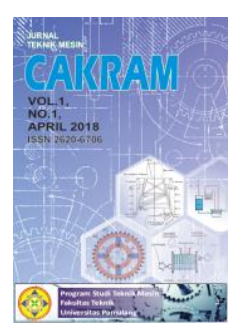

\title{
PERLAKUAN TERMOMEKANIK PADUAN TITANIUM HASIL CORAN VACCUM ARC MELTING
}

\author{
Fendy Rokhmanto \\ Program Studi Teknik Mesin, Fakultas Teknik, Universitas Pamulang \\ E-mail : fendy.rokhmanto@gmail.com
}

Masuk : 16 Februari 2021

Direvisi : 5 Maret 2021

Disetujui : 17 Maret 2021

\begin{abstract}
Abstrak: Titanium dan paduanya merupakan salah material logam yang tangguh, sehingga banyak diaplikasikan pada aerospace, marine, oil and gas, biomedical, olah raga, otomotif dan lain-lain. Produk Titanium, dapat diperoleh dari beberapa proses manufaktur yaitu casting, machining, forming, dan powder metallurgy. Produk akhir, ingot hasil coran ataupun produk setengah jadi paduan Titanium dapat dimodifikasi sifat mekanisnya dengan proses heat treatment dan thermomechanical treatment. Pada penelitian ini dilakukan investigasi perubahan sifat mekanis dalam hal ini kekerasan dan struktur mikro paduan titanium. Ingot paduan Titanium Ti-Al-Nb dibuat dengan proses remelting logam paduan dalam tungku busur lustrik vakum. Kemudian ingot hasil coran dilakukan proses homogenisasi pada temperatur 1100 ${ }^{\circ} \mathrm{C}$ selama 12 jam dengan pendinginan didalam tungku dan dilanjutkan dengan hot roll dengan pemanasan awal 1100 ${ }^{\circ} \mathrm{C}$ dan waktu tahan 1 jam yang kemudian dilakukan quenching. Karakterisasi paduan dilakukan pada setiap kondisi perlakuan, adapun karakterisasinya adalah pengamatan stuktur mikro menggunakan foto metalografi, SEM dan uji keras dengan metode Rockwell C. Pengamatan metalografi menunjukkan bahwa paduan merupakan alfa-beta Titanium. Proses pengulangan remelting tidak memberikan efek signifikan terhadap peningktan kekerasan paduan. Proses thermomekanikal treatment mengakibatkan perubahan bentuk mikrostruktur dari interdendritic menjadi platelike dan nilai kekerasan menjadi $52 \mathrm{HRc}$ pada 3 kali remelting dan $50.5 \mathrm{HRc}$ pada 5 kali remelting
\end{abstract}

Kata kunci: titanium, vacuum arc melting, termomekanik, pengecoran

Abstract: Titanium and its alloys are widely used, such as in aerospace, marine oil and gas, biomedical, sports, automotive and others, because of the toughness of the materials. Casting, machining, forming, and powder metallurgy are the manufacturing process for making titanium products. The properties of the ingots, intermediate product and also the end product of titanium can be modified with heat treatment and thermomechanical treatment. This paper studied the hardness and phase transformation during the thermomechanical treatment of titanium alloys, Ti-Al-Nb. The ingot was prepared by vacuum arc melting, then homogenized at $1100{ }^{\circ} \mathrm{C}$ for 12 hours, with furnace cooling. After that, the alloys were hot rolled with preheat at $1100{ }^{\circ} \mathrm{C}$ for 1 hour followed by water quenching. The alloys were characterized with an optical microscope and SEM to investigate the microstructure and Rockwell C test to investigate the hardness. The metallographic shows that the alloys are alpha-beta titanium with the inter-dendritic structure in an as cast product that transforms to plate like structure after the thermomechanical process. The thermomechanical process also affected the hardness up to 52 HRc in 3 times remelting and 50.5 HRc in 5 times remelting, but the remelting not any significant difference at as cast condition

Keywords: titanium, vacuum arc melting, thermomechanical process, casting 


\section{PENDAHULUAN}

Titanium dan paduanya merupakan salah material logam yang tangguh, sehingga banyak diaplikasikan pada berbagai macam bidang kehidupan. Beberapa bidang aplikasinya antara lain pada industri aerospace, marine, oil and gas, biomedical, olah raga, otomotif dan lain-lain[1,2]. Ketangguhan yang dimiliki oleh paduan Titanium, secara mikroskopis dipengaruhi oleh fasa-fasa yang terbentuk dalam padaan. Fasa-fasa ini juga dijadikan sebagai pengklasifikasian tipe padan Titanum, yaitu $\alpha$ Titanium, $\alpha-\beta$ titanium dan $\beta$ Titanium[1,2]. Fasa alfa yang mempunyai strukur kirstal HCP, dalam paduan distabilkan oleh beberaa unsur antara lain, Nitrogen, Oksigen, dan Alumunium, sedangkan fasa beta yang mempunyai strukur kirstal BCC distabilkan oleh, Vanadium, Ferrous, Chromium, Molydenum, dan Niobium[1,2].

Produk Titanium, dapat diperoleh dari beberapa proses manufaktur yaitu casting, machining, forming, dan powder metallurgy[1]. Produk akhir, ingot hasil coran maupun produk setengah jadi paduan Titanium dapat dimodifikasi sifat mekanisnya dengan proses heat treatment dan thermomechanical treatment. Proses tersebut dilakukan pada temperatur diatas temperatur beta transus yaitu $995^{\circ} \mathrm{C}[3]$, hal ini dikarenakan diatas temperataur tersebut paduan berada dalam fasa beta dengan struktur kristal BCC sehingga mudah untuk dibentuk.

Pada penelitian ini dilakukan investigasi pada perubahan sifat mekanis dalam hal ini kekerasan paduan dan struktur mikro paduan titanium, dalam kondisi ingot hasil coran dan setelah proses heat treatment dan thermomechanical treatment. Ingot paduan yang digunakan adalah Ti-Al-Nb hasil pengecoran dengan tungku busur listrik vakum (vaccume arc melting).

\section{METODOLOGI}

Ingot paduan Titanium dibuat dengan proses remelting logam paduan dangan berat ingot 20 gram. Logam paduan yang digunakan adalah Alumium dan Niobium, dengan kompisisi 6\% dalam persen berat dan sisanya adalah Titanium. Tiga logam paduan tersebut dilelehkan ulang dalam tungku busur lustrik vakum, yang kemudian diulang sebanyak 3 kali dan 5 kali, sedemikian hingga paduan terbentuk secara homogen. Kemudain ingot hasil coran dilakukan proses homogenisasi pada temperatur $1100^{\circ} \mathrm{C}$ selama 12 jam dengan pendinginan didalam tungku dan dilanjutkan dengan pengerolan dengan pemanasan awal $1100{ }^{\circ} \mathrm{C}$ dengan waktu tahan 1 jam yang kemudian dilakukan quenching. Karakterisai padauan dilakukan pada setiap kondisi perlakuan, adapun karakterisasinya adalah pengamatan stuktur mikro menggunakan foto metalografi, SEM-EDX dan uji keras dengan metode Rockwell C.

\section{HASIL DAN PEMBAHASAN}

Gambar 1 adalah struktur mikro paduan Ti-Al-V yang merupakan salah satu paduan alfa beta yang banyak digunakan di industri. Gambar 2 dan Gambar 3 adalah foto struktur mikro paduan titanium Ti-6Al-6Nb, dengan kondisi remeliting 3 kali dan 5 kali. Gambar 2a dan Gambar 3a padauan dalam hasil coran, tampak terbentuk fasa alfa pada batas butir dengan warna lebih cerah dan fasa beta lebih gelap. Hal ini mirip dengan paduan Ti-Al-V, seperti yang tampak pada gambar 1 dan mirip dengan penelitian paduan alfa-beta terdahulu yaitu Ti-Al-Mo[4-6]. Gambar 2b dan Gambar 3b setelah dilakukan homogenaisai, fasa yang terbentuk adalah plate-like alfa dan fasa beta yang tersebar di dalam butir, yang tampak seperti struktur perlit dalam baja. Secara kualitatif fasa alfa yang terbentuk juga menjadi lebih besar, hal ini sesuai dengan innvestigasi yang dilakukan oleh C. Sutowo pada penelitian terdahulu[7]. Pada proses remelting 3x plate-like alfa yang terbentuk lebih kecil bila dibandingkan dengan 5x remeliting. Gambar 2c dan Gambar 3c setelah proses hot roll, tampak struktur butiran menjadi lebih pipih dan memanjang searah rolling dirction. Gambar 4 dan Gambar 5 adalah foto SEM paduan titanium Ti-6Al-6Nb, dengan kondisi remeliting 3 kali dan 5 kali. Tampak bahwa terbentuk fasa alfa dan fasa beta. Fasa yang terbentuk bertansformasi dari interdenritic pada kondisi as cast menjadi lamelar atau plate-like pada kondisi setelah perlakuan panas. Pada perbesaran 1000x tampak bahwa bentuk plate-like alfa terbentuk pada batas butir, sehingga nampak butiran menjadi lebih kecil setelah proses homogenisasi (5b) dibandingkan dengan kondisi as cast (2a). 


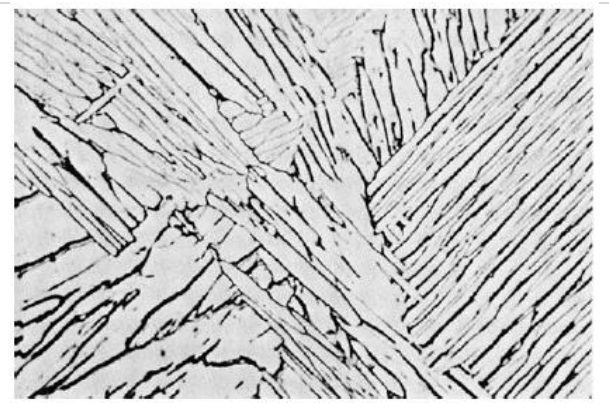

Gambar 1. Struktur mikro padauan Ti-Al-V [1]
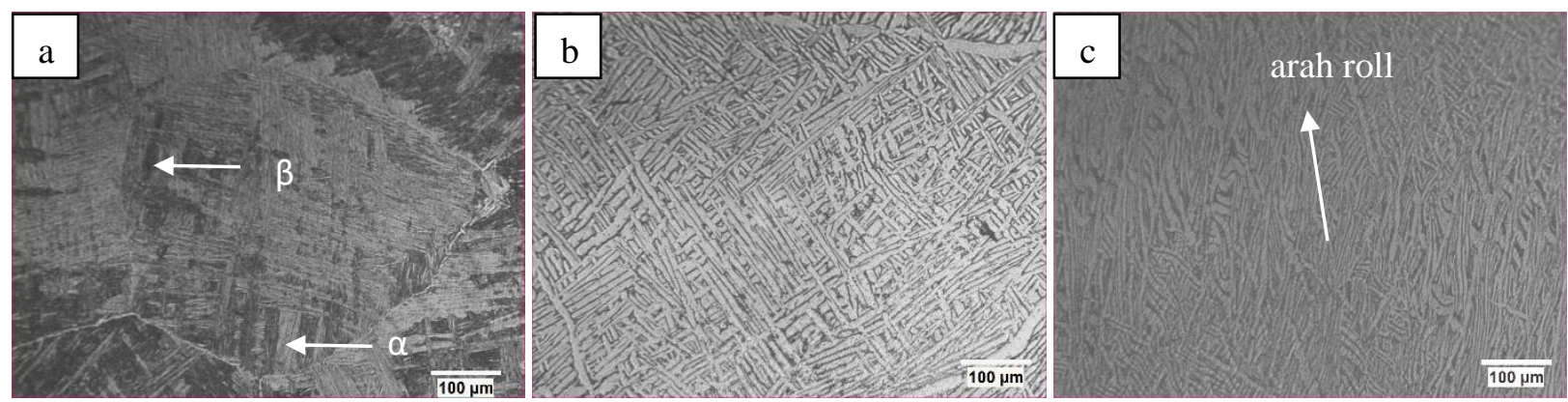

Gambar 2. Struktur mikro padauan Ti-6Al-6Nb 3 kali remelting: as cast (a), homogenisai (b), hot roll (c), Perbesaran 200x. Etsa $\mathrm{HF}: \mathrm{HNO}_{3}: \mathrm{H}_{2} \mathrm{O}=10: 5: 85$
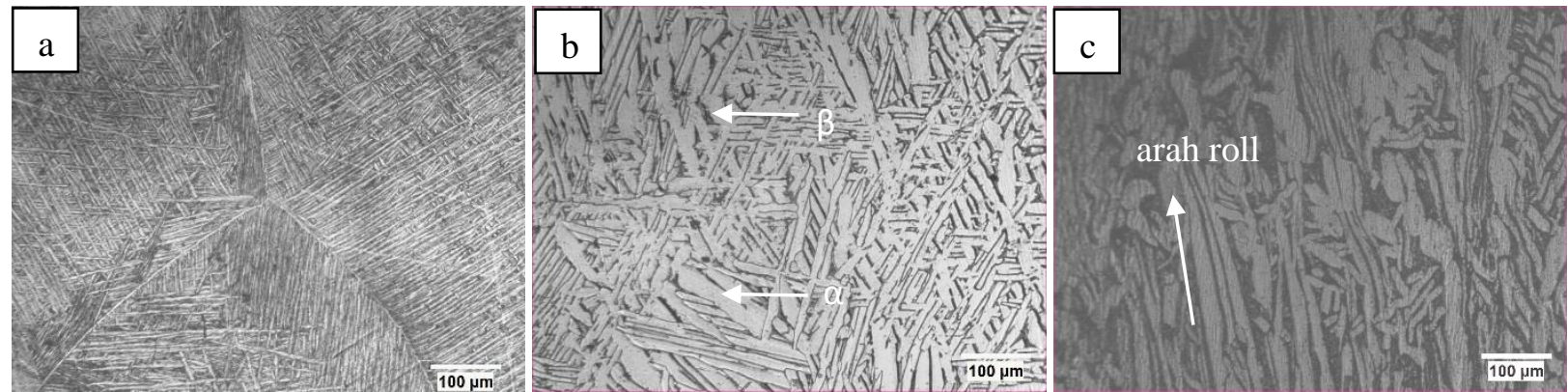

Gambar 3. Struktur mikro padauan Ti-6Al-6Nb 5 kali remelting: as cast (a), homogenisai (b), hot roll (c), Perbesaran 200x. Etsa $\mathrm{HF}: \mathrm{HNO}_{3}: \mathrm{H}_{2} \mathrm{O}=10: 5: 85$
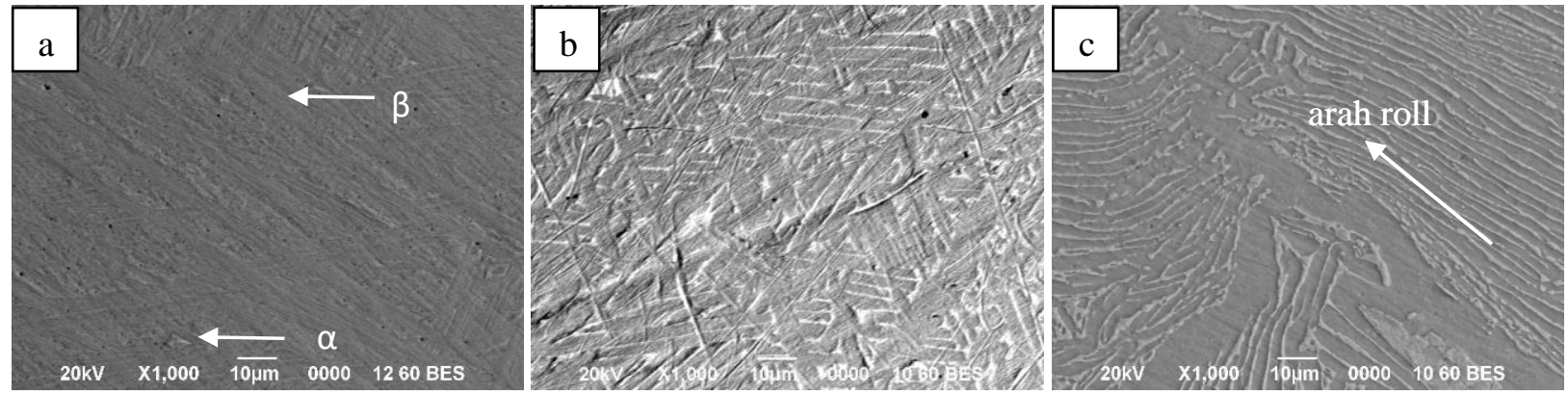

Gambar 4. Foto SEM Ti-6Al-6Nb 3 kali remelting: as cast (a), homogenisai (b), hot roll (c), Perbesaran 1000x. 

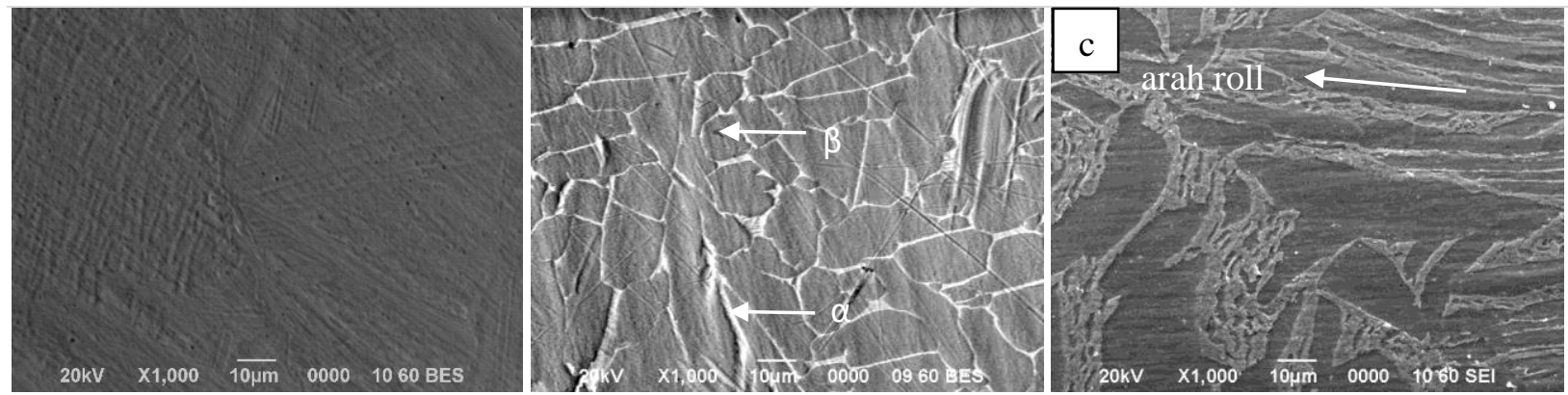

Gambar 5. Foto SEM Ti-6Al-6Nb 5 kali remelting: as cast (a), homogenisai (b), hot roll (c), Perbesaran 1000x.

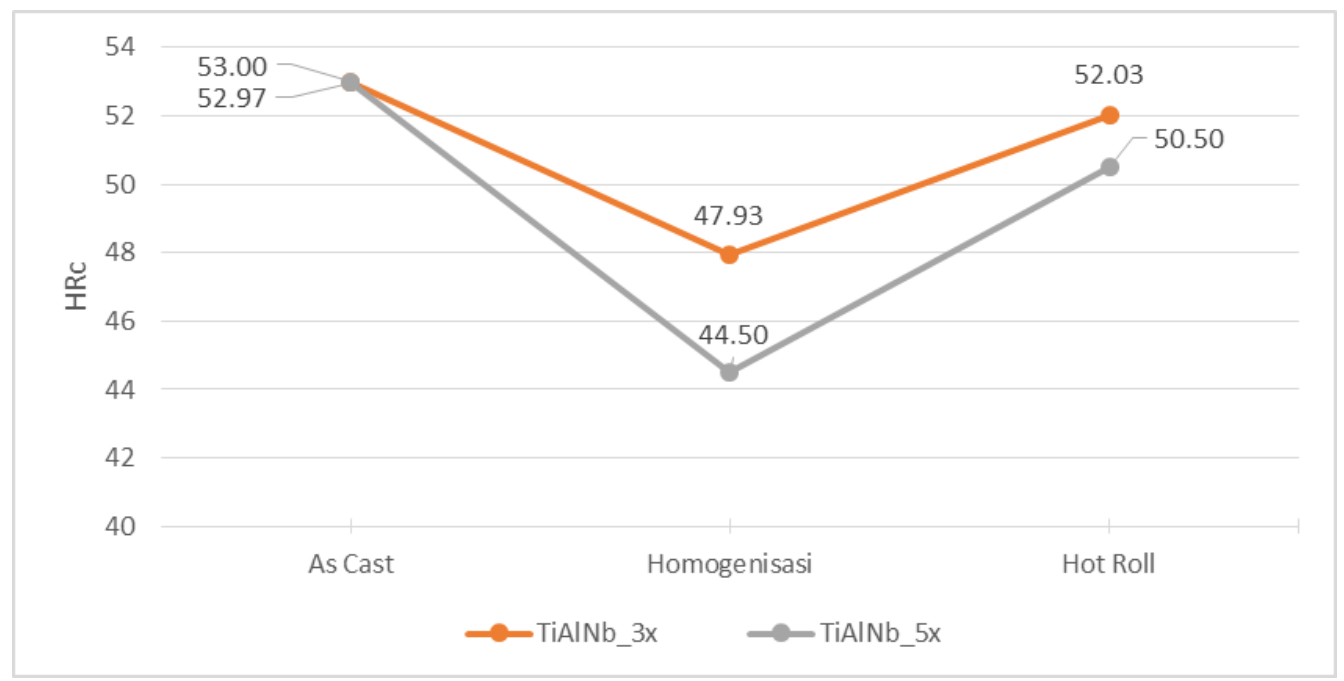

Gambar 6. Grafik uji keras ingot paduan Ti-6Al-6Nb

Gambar 6. merupakan grafik hasil uji keras paduan Ti-6Al-6Nb. Tampak bahwa pada konidisi as cast nilai kekerasan adalah $53 \mathrm{HRc}$. Nili kekerasan pada perlakuan 3 kali dan 5 kali proses remelting tidak menunjukkan perbedaan, hal ini mengindikasikan bahwa variasi proses remelting tidak memberi dampak apapun pada kekerasannya. Dapat juga disimpulkan bahwa tidak perlu dilakukan pengulangan remelting karena paduan sudah homogen, dan tidak terjadi segregasi kimia. Hal ini juga dapat dilihat pada hasil metalografi, strukmur mikro yang tampak juga identik diantara keduanya (Gambar 2a dan Gambar 3a).

Pada kondisi setelah homogenisasi nilai kekerasan turun menjadi 48 HRc pada kondisi 3 kali remelting dan menjadi 44.5 HRc pada kondisi 5 kali remelting. Penurunan nilai kekerasan ini dikarenakan hilangnya struktur interdendritic khas produk coran yang bersifat keras dan getas, menjadi struktur lamellar atau plate-like. Nilai kekerasan pada proses 3 kali remelting lebih tinggi bila dibandingkan dengan kondisi 5 kali remelting, hal dikarenakan oleh struktur plate like pada 3 kali remelting lebih kecil atau lebih halus. Demikian halnya pada baja ketika memliki struktur perlit yang lebih halus maka baja tersebut lebih keras bila dibandingkan dengan struktur perlit yang lebih kasar, hal ini berkaitan dengan dislokasi dan pengerasan regangan yang terjadi di dalamnya. Dislokasi dan pengerasan regangan juga berperan meningkatkan kekerasan setelah dilakukan prosess pengerolan[8]. Hal ini diakibatkan karena mekanisme work hardening, dalam penelitian ini adalah proses hot rolling yang juga menimbulkan tegangan sisa hingga mengakibatkan kekerasan paduan mencapai lebih dari 50 HRc. Peningkatan kekerasan pada paduan Titanium selain karena porses pengerolan[9], juga diakibatkan adanya pembentukan fasa intermetalik $\mathrm{TiAl}_{3}$, yang disebut sebagai fasa alfa dengan struktur kristal HCP[10]. 


\section{KESIMPULAN}

Karakterisasi paduan Titanium Ti-6Al-6Nb telah dilakukan. Pengamatan metalografi menunjukkan bahwa paduan merupakan alfa-beta titanium, diindikasikan dengan terbentuknya fasa alfa dan beta. Proses pengulangan remelting tidak memberikan efek signifikan terhadap peningktan kekerasan paduan. Proses thermomekanikal mengakibatkan perubahan bentuk mikrostruktur dari interdendritic menjadi plate like dan nilai kekerasan menjadi 52 HRc pada 3 kali remelting dan 50.5 HRc pada 5 kali remelting

\section{DAFTAR PUSTAKA}

[1] Matthew J. Donachie, Jr, 2000 “Ti A Technical Guide”, The Material Information Society, ASM Hand Book, Second Edition.

[2] C. Leyens and M. Peters, 2003, “Titanium and Titanium Alloys Fundamentals and Applications.”, WILEYVCH Verlag GmbH \& Co. KGaA, Weinheim.

[3] Obasi, G.C. et al., 2012. "The Influence of Rolling Temperature on Texture Evolution and Variant Selection During $\alpha \rightarrow \beta \rightarrow \alpha$ Phase Transformation in Ti-6Al-4V”. Acta Materialia, 60 (17), pp.6013-6024.

[4] Cahya Sutowo. dkk., 2017., "Proses Perlakuan Termomekanis pada Paduan $\alpha / \beta$ Ti-6Al-6Mo sebagai Alternatif Baru untuk Aplikasi Biomedis", Widyariset. Vol. 3 No. 1 Hlm. 47 - 54

[5] Fendy Rokhmanto. dkk., 2016., "Perlakuan Termomekanikal Ingot Paduan Ti-Al-Mo"., Prosiding Seminar Nasional Sains dan Teknologi 2017., Fakultas Teknik Universitas Muhammadiyah Jakarta , 8 November 2016.

[6] Cahya Sutowo. dkk ., 2016., "Pembentukan Struktur Mikro Paduan Titanium Ti6Al6Mo As Cast Sebagai Bahan Dasar Implan.”., Prosiding Seminar Nasional Sains dan Teknologi 2017., Fakultas Teknik Universitas Muhammadiyah Jakarta , 8 November 2016.

[7] Fendy Rokhmanto., et al., 2017., "Influence of Solution Treatment Cooling Medium on Microstructure and Elastic Modulus Ti-6Al-6Mo For Biomedic Applications"., Proceedings of the International Seminar on Metallurgy and Materials (ISMM2017)., https://doi.org/10.1063/1.5038331.

[8] Callister, W.D. \& Wiley, J., Materials Science, 2009, "Materials science and engineering: an introduction", John Wiley \& Sons, Inc. Eight Editon.

[9] Fendy Rokhmanto. dkk., 2017.,“ Perlakuan Termomekanikal Paduan Ti-Al-V Sebagai Material Implan”, Prosiding Seminar Nasional Sains dan Teknologi 2017., Fakultas Teknik Universitas Muhammadiyah Jakarta, 1-2 November 2017.

[10] Ninomi Mitsuo, 1998 "Mechanical Properties of Biomedical Ti Alloys", Elsevier Material Science and Engineering A 243 231-236. 